\title{
Alteridade, ética e integridade em um mundo de consumidores: o que o caso Me Gusta Picolés Artesanais nos ensina?
}

\author{
Alterity, ethics and integrity in a world of consumers: what does the \\ Me Gusta Picolés Artesanais case teach us?
}

\section{Alteridad, ética e integridad en un mundo de consumidores: ¿qué nos enseña el caso Me Gusta Picolés Artesanais?}

\section{Marcelo Pereira da Silva}

- Doutor em Comunicação Social pela Universidade Metodista de São Paulo (Umesp)

- Mestre em Comunicação Midiática pela Universidade Estadual Paulista Júlio de Mesquita Filho (Unesp)

- Graduado em Relações Públicas pela Unesp

- Professor da Pós-graduação em Formação de Soldados na Polícia Militar do Maranhão

- Professor permanente do Mestrado em Cultura e Sociedade e do curso de Relações Públicas na Universidade Federal do Maranhão (UFMA)

- E-mail: marcelosilva_rp@hotmail.com

Jéssica de Cássia Rossi

- Doutora em Ciências Sociais pela Universidade Estadual Paulista Júlio de Mesquita Filho (Unesp)

- Mestre em Comunicação pela Unesp

- Graduada em Comunicação Social com habilitação em Relações Públicas pela Unesp

- Professora de Relações Públicas na Universidade do Sagrado Coração (USC)

- E-mail: jessicacrossi@yahoo.com.br

\section{Ana Carolina Trindade}

- Mestranda em Comunicação pela Universidade Estadual Paulista Júlio de Mesquita Filho (Unesp)

- MBA em Comunicação e Marketing pela Universidade Cruzeiro do Sul (Unicsul)

- Especialização lato sensu em Linguagem, Cultura e Mídia pela Unesp

- Graduada em Relações Públicas pela Universidade Sagrado Coração (USC)

- Membro do Grupo de Pesquisa Comunicação Midiática e Movimentos Sociais (ComMov)

- E-mail: carolinatrin@gmail.com 


\section{Resumo}

Em nossa sociedade ambivalente, valores como ética e respeito são condições para a construção de um mundo melhor no qual as diferenças possam coabitar apesar das conflitualidades, desafiando organizações e stakeholders em um contexto de fácil conexão e exposição de críticas, indignações e decepções. Assim, analisamos, por meio de pesquisa literária e estudo de caso, o posicionamento da Me Gusta Picolés Artesanais diante da atitude de um funcionário, inferindo que a coragem do amor se mede pelo reconhecimento das diferenças e, não obstante, ser capaz de acolher essa alteridade.

PALAVRAS-CHAVE: COMUNICAÇÃO ORGANIZACIONAL • ME GUSTA PICOLÉS ARTESANAIS •ÉTICA • SOCIEDADE DE CONSUMO • DISCURSO.

\section{Abstract}

In our ambivalent society, values such as ethics and respect are conditions for building a better world in which differences can cohabit despite conflicts, challenging organizations and stakeholders in a context of easy connection and exposure of criticism, indignation and deception. Therefore, we analyze, through literary research and case study, the positioning of Me Gusta Picolés Artesanais in the attitude of an employee, inferring that the courage of love is measured by the recognition of differences and yet be able to accept this alterity.

KEYWORDS: ORGANIZATIONAL COMMUNICATION • ME GUSTA PICOLÉS ARTESANAIS • ETHICS•CONSUMER SOCIETY • DISCOURSE.

\section{Resumen}

En nuestra sociedade ambivalente, valores como ética y respeto son condiciones para la construcción de un mundo mejor en el que las diferencias puedan cohabitar pese los conflictos, desafiando organizaciones y stakeholders en un contexto de fácil conexión y exposición de críticas, indignaciones y decepciones. De ese modo, analizamos, a través de investigación literaria y estudio de caso, el posicionamiento de la Me Gusta Picolés Artesanais delante de la actitud de un empleado, infiriendo que el coraje al amor se mide por el reconocimiento de las diferencias y, no obstante, ser capaz de acoger esa alteridad. 
$\dot{E}$

tica, respeito e integridade são valores que podem - e devem - fundamentar Estados, organizações e sujeitos, sobretudo, em um contexto no qual impera a corrupção, a mentira e a insensibilidade às alteridades. Ao considerarmos que estamos em uma sociedade pós-moderna - permeada pelas tecnologias da informação e comunicação - e que os públicos utilizam as mídias digitais para disseminar posicionamentos de mundo, destacamos a necessidade de uma comunicação organizacional bidirecional, dialógica e interativa, na qual o fluxo das mensagens entre o emissor e receptor sejam humanos e democráticos, tornando mais eficaz a participação, a manifestação dos stakeholders e a interação com eles.

A capacidade de expressão e compartilhamento entre os sujeitos cresceu vertiginosamente no cenário on-line. Com isso, a velocidade na troca de informações proporciona maior facilidade na exposição de críticas, injúrias e difamação das organizações na web, levando-as a compreenderem o perfil dos seus consumidores e pautarem suas ações em uma comunicação ancorada na verdade', primando por relacionamentos sinceros com seus públicos de interesse.

O princípio de dialogar e respeitar deve ser uma condição essencial, haja vista estabelecer, manter e aprimorar as relações entre as organizações e seus públicos, gerando a possibilidade da convivência no universo consumerista contemporâneo. As relações com os stakeholders constituem o elemento basilar da comunicação organizacional (Kunsch, 2016; Semprini, 2006; Simões, 2001; Silva, 2016). A atenção às manifestações e indignações dos consumidores cresce potencialmente nas mídias digitais. Isso exige que as marcas invistam tempo para nutrir, reafirmar e reforçar o relacionamento com seus interlocutores no mundo off-line e on-line.

Por isso, analisamos o caso da empresa Me Gusta Picolés Artesanais, de 2015, depois de um casal homossexual ser expulso do seu estabelecimento em São Paulo, erigindo questionamentos e reflexões acerca da relevância de as organizações adotarem práticas mais honestas e abertas com os seus públicos na sociedade contemporânea que é, essencialmente, complexa. Lançamos luz sobre a necessidade urgente da comunicação normativa, haja vista valorizar o diálogo e a compreensão, permitindo a construção de um mundo melhor (Morin, 2011, 2015), eivado de possibilidades e práticas éticas.

\section{A COMUNICAÇÃO ORGANIZACIONAL EM UM MUNDO DE CONSUMIDORES}

Nossa civilização é incitada ao hiperconsumo, criando um mundo de consumidores (Bauman, 2011). Morin (2015, p. 301-302) defende que o "consumo se transforma em consumismos nos quais o supérfluo torna-se indispensável" e os antigos luxos passam a ser necessidades. Assim, o consumo estrutura e reestrutura as dinâmicas sociais por ser um processo sociocultural, simbólico, político e econômico. A partir do momento em que as identidades passam a ser definidas pela lógica do "eu consumo, eu sou, eu posso, eu mereço", o fenômeno ganha status de protagonismo, pois o ato de consumir é constitutivo do sujeito. Além disso, passa a caracterizar e denominar a ambivalente sociedade pós-moderna.

0 consumo se apresenta como algo significativo na sociedade atual e pode ter o propósito, muitas vezes, de colaborar com os indivíduos para exercerem a cidadania. Isso é possível pelo fato de os indivíduos compreenderem que diversas perguntas relacionadas à cidadania podem ser mais bem respondidas "através do consumo privado de bens e dos meios de comunicação de massa do que pelas regras abstratas da democracia ou pela participação coletiva em espaços públicos" (Canclini, 2010, p. 29). Esse quadro permite a transformação de consumidores em cidadãos.

1 "Transparência" é um termo que aparece, amiúde, no discurso das organizações. Optamos, porém, por usar as palavras "verdade" e "honestidade", posto que ser transparente, segundo Han (2012 apud Dreyer, 2017), refere-se à comunicação de uma agenda positiva das ações corporativas enquanto a verdade reconhece erros, aceita as críticas, interage com a indignação dos consumidores e públicos de afinidade. 
A sociedade de consumo gera uma orla de consumidores competentes e "o encolhimento implacável do mundo habitado pelos desqualificados", segundo Bauman (1999, p. 274). Assim, a sociedade divide-se em metades: a dos afortunados seduzidos e a dos infelizes oprimidos. Nessa dicotomia, celebra-se a bênção da primeira metade e se aumenta a miséria da segunda. Estando lá ou cá, a vida do consumidor não se amarra exclusivamente à aquisição e posse, "tampouco tem a ver com se livrar do que foi adquirido anteontem e exibido com orgulho no dia seguinte. Refere-se, em vez disso, principalmente e acima de tudo, a estar em movimento" (Bauman, 2008, p. 126, grifo do autor).

Esse movimento vai do consumo ao consumismo. Bauman (2011, p. 83) concebe o consumismo como "a tendência a situar a preocupação com o consumo no centro de todos os demais focos de interesse e quase sempre como aquilo que distingue 0 foco último desses interesses". 0 consumismo espreita os sujeitos na medida em que a sociedade de consumidores inferioriza a durabilidade, equiparando os termos velho e defasado, impróprio para seguir sendo utilizado e destinado à lata de lixo. $\mathrm{A}$ reduzida expectativa de vida de um produto faz parte das estratégias de marketing, no cálculo dos lucros e no envolvimento do consumidor, o que ocorre, segundo Bauman (2008, p. 31), mediante a "apoteose das novas ofertas (de hoje) e a difamação das antigas (de ontem)". Na esteira desse pensamento, Morin (2015) assevera que o estímulo publicitário conduz a compras de produtos e serviços, muitas vezes, dotados de virtudes ilusórias.

A revolução do consumismo ganhou força após a Segunda Guerra Mundial e sua realização transcendeu o ideário moderno de controle da sociedade por meio do trabalho, avançando à esfera particular, em cuja natureza se encontra uma nova costura: flutuação dos princípios, status e papéis, "velocidade veloz" da moda, dessubstancialização e desreferencialização do sujeito etc. Tudo isso se desloca sobre um self-service generalizado, "absorvendo o indivíduo na corrida pelo nível de vida e [...] a busca da realização de si mesmo" (Lipovetsky, 2005, p. 84). Para Morin (2015), o consumismo conduz ao superconsumo, denominado "consumerismo"2, estimulado pela obsolescência rápida dos produtos e serviços.

Assim, valores que fundamentam as relações sociais, tais como ética, respeito e integridade, tornam-se condicionais para a construção de um mundo mais justo e sustentável. Paradoxalmente, tais valores colidem com a cultura de consumo na qual as relações se constroem. 0 que podemos esperar não é o melhor dos mundos, mas um mundo melhor, ainda que a falta de sentido cimente as interações humanas.

\section{ÉTICA, INTEGRIDADE E COMUNICAÇÃO ORGANIZACIONAL NUM MUNDO EM BUSCA DE SENTIDO}

Vivemos em um mundo que busca e anseia por sentido. Lipovetsky e Serroy (2011, p. 31) afirmam que, enquanto o sentimento de vazio se expande, proliferam os comportamentos "inebriantes para escapar à noite de um mundo sem valor, ao abismo da falta de objetivo e de sentido". Embora a sociedade hodierna permaneça em constante transformação devido aos avanços tecnológicos atuais, ainda estamos distantes de um mundo em que as relações sociais são regidas pelo respeito às alteridades.

Srour (2012, p. 229) postula que a ética "diz respeito ao impacto que agentes sociais provocam uns sobre os outros em função de suas decisões e ações", em que o contemporâneo acarretou diversas discussões e, entre elas, a "perda" de força da ética. Discute-se, assim, a crise ética na pós-modernidade. Para Bauman (2003), essa crise se deve às atitudes pessoais dos indivíduos que geram grandes consequências e alcançam diversas áreas, ocasionando certa impotência das normas éticas que se aprendem ao longo da vida. As atitudes são oriundas de escolhas que não têm intenções predeterminadas como benéficas

2 Morin (2015) refere-se, sociologicamente, a uma ideologia econômica na qual o consumo de bens, serviços e marcas ocupa um espaço primordial na sociedade contemporânea. 
ou maléficas e, por isso, resultam em consequências que não dão possibilidade de mensurar o alcance no tempo e espaço, dado que a ética não foi feita à medida dos poderes que possuímos (Bauman, 2003).

Nesse sentido, a era pós-moderna torna-se propulsora em relação à oportunidade de encarar, segundo Bauman (2003, p. 43), "a capacidade moral humana sem rebuços", considerando que esse tempo tem como possibilidade o reencantamento da sociedade, uma vez que passa a viver sem ilusões, falsas consciências, aspirações irreais ou objetivos irrealizáveis.

$O$ reencantamento pós-moderno possibilita a vivência tal como ela é, sem ilusões ou lembranças do "estigma deixado pelas desconfianças modernas" (Bauman, 2003, p. 43). Essa nova reconfiguração origina um mundo mais realista e humano. Ao encontro desse pensamento, Almeida (2007) defende que os princípios morais e valores devem ser levados em consideração pelas organizações classificadas como éticas, visto que poderão alcançar êxito quando sua ação e seu discurso forem concatenadas à moral vigente.

A ética transcende conceitos fechados e sem modificações. A integridade humana e seus valores podem erigir um novo mundo, transformando a realidade social. Para tanto, a verdade deve ser uma qualidade intrínseca aos indivíduos, organizações e Estados, posicionando a comunicação como um processo de gestação da convivência dos contraditórios e gestão das conflitualidades.

\section{COMUNICAÇÃO ORGANIZACIONAL: ONDE ESTÃO OS COMUNICADORES E SUA ÉTICA?}

O contexto pós-moderno tem influenciado na forma como as organizações se comunicam com seus stakeholders. Para a comunicação organizacional, o relacionamento com esses grupos deveria ocorrer por meio da comunicação bidirecional, na qual as empresas buscam dialogar e negociar interesses a fim de gerenciar as decepções e conflitualidades. Entretanto, por vezes, algumas organizações impõem suas vontades, usando um modelo de comunicação unidirecional que não dá voz aos receptores, ignorando que hoje são mais ativos e participantes.

Os stakeholders querem que as empresas os ouçam, "mas também [estão] mais diferentes e exigentes em suas identidades, estilos e vocabulários" (Wolton, 2006, p. 14). Nessa perspectiva, as relações consumeristas e interpessoais pautam-se, principalmente, pela dimensão funcional da comunicação, na qual as informações são utilizadas apenas com fins pragmáticos, enquanto a dimensão normativa, que privilegia o diálogo e a compreensão, é desvalorizada. Para o Wolton (2006), deveria ocorrer o equilíbrio dessas dimensões da comunicação nas relações sociais. Contudo, muitas vezes, as organizações preocupam-se apenas em produzir informações e divulgá-las para seus públicos, sem ouvi-los, e a negociar sentidos, o que pode gerar um contexto de (in)comunicação ${ }^{3}$.

A comunicação organizacional precisa ser estratégica, ter uma visão interdisciplinar e enxergar as demandas dos públicos que exigem atitudes éticas e responsáveis, além de respeito pelo planeta (Kunsch, 2016). Isso significa identificar antecipadamente possíveis problemas e interesses dos públicos e buscar resolvê-los com abertura, reciprocidade e disposição. A comunicação se faz presente nos diferentes processos simbólicos, por isso deve enfocar nos sentidos produzidos pelos agentes envolvidos, valorizando as interações nas suas variadas formas de manifestação, representação e construção social.

As mídias digitais também acentuam a relevância da comunicação organizacional estratégica. As empresas não controlam as atitudes dos públicos, na verdade, elas precisam ter um relacionamento interativo com eles, pois também são produtores

3 Entendemos a incomunicação como o horizonte da comunicação (Wolton, 2006). Trata-se de um fruto do aperfeiçoamento da democracia e da participação, podendo gerar a convivência de pontos de vista contraditórios. 
de mensagens, dado que houve uma reconfiguração da noção de públicos, em que "multidirecionalidade, equivalência de vozes e autogeração de conteúdos são algumas das posturas decorrentes desse cenário" (Corrêa, 2016, p. 69). Essa pressão para a mudança de posicionamento entre empresas e públicos tornou-se uma exigência social e do mercado. É necessário que dialoguem com os públicos, atentem-se ao que está acontecendo e, acima de tudo, sejam éticas e honestas em suas atuações e discursos.

A ação e o discurso corporativos devem ser coerentes; mais do que "parecer ser", as organizações devem ser e praticar 0 que dizem. Adotar ações de marketing verde, social etc. apenas para projetar suas marcas é uma atitude rasa em relação ao que os stakeholders esperam. As empresas devem ser responsáveis ambientalmente e socialmente, mas, sobretudo, éticas e íntegras em suas atitudes. Na visão de Bueno (2014), muitas organizações alegam que possuem responsabilidade socioambiental, mas é necessário que se averigue aquelas que realmente são íntegras em suas posições e discursos.

Nessa seara, os profissionais da comunicação, por sua vez, também devem evitar que situações falaciosas ocorram, já que têm um papel moral em sua atuação e no resultado estratégico de suas atividades, juntamente com as organizações. Essa responsabilidade pode ser compreendida pelo que Simões (2001) chamou de ética e estética ao abordar o exercício das relações públicas. Para o autor, a ética enleia-se à "legitimidade da ação e do discurso organizacional", enquanto a estética trata do "bem pensado, planejado e executado" (Simões, 2001, p. 41). Assim, a atuação ética da organização, sob a responsabilidade do profissional de comunicação, ocorre por sua atuação responsável socioambientalmente, não por discursos alienantes pois, desse modo, buscará esteticamente a conciliação de interesses e atuará estrategicamente a fim de evitar o desfuncionalizar estético corporativo, o qual associa as organizações a ações e discursos considerados inadequados e anacrônicos.

Por isso, não é somente o que as empresas informam que pode influenciar nos comportamentos e atitudes de seus públicos, mas também o que elas fazem. Nesse universo, a Me Gusta Picolés Artesanais apresenta-nos um caso relevante que nos leva a problematizar o lugar que organizações e públicos de interesse ocupam na construção de um mundo mais ético, íntegro e respeitável, no qual possamos reconhecer as virtudes do Outro ${ }^{4}$ e a necessidade da coabitação. 0 amor $^{5}$, enquanto ato fundador da vida, é "precondição de humanidade, civilização e humanidade civilizada" (Bauman, 2011, p. 39), servindo como alicerce para um mundo em busca de sentido e compreensão.

A compreensão se viabiliza, conforme Morin (2011, p. 180), por meio de uma ética da compreensão que oblitere o "programa" ocidental perpassado pelo egocentrismo e rume a um "programa" altruísta, ancorado na solidariedade e na compaixão. Embora toda metamorfose pareça impossível antes de acontecer, "essa constatação possui um princípio de esperança". A Me Gusta Picolés Artesanais nos ensina muito acerca disso.

\section{O CASO ME GUSTA PICOLÉS ARTESANAIS - HISTÓRICO E CONTEXTO}

A sorveteria Me Gusta Picolés Artesanais ${ }^{6}$ localizava-se na rua Augusta, uma movimentada região de São Paulo. Em seu cardápio, a originalidade e o sucesso eram atribuídos aos diversos sabores de picolés recheados com pedaços de frutas frescas e 100\% artesanais ${ }^{7}$. A visão da empresa era semelhante à cosmovisão de seus idealizadores, "por isso respeito,

4 Escrevemos "Outro" com a letra "0" maiúscula por o compreendermos na sua unicidade, particularidade e especialidade.

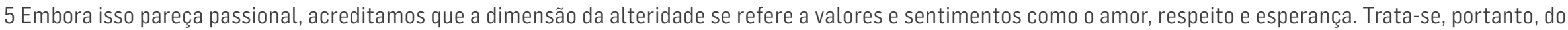
caminho que escolhemos para dar uma resposta às aporias da sociedade pós-moderna.

6 A Me Gusta Picolés Artesanais foi inaugurada em março de 2014 e encerrou suas atividades no dia 30 de setembro de 2016.

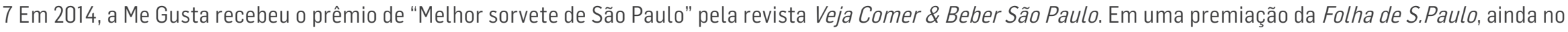
mesmo ano, foi eleita como a fabricante do "Melhor Picolé de Morango com Leite Condensado de São Paulo". 
comprometimento, dedicação, responsabilidade e amor ao próximo são além de nossos valores nossa maneira de buscar a satisfação de nossos clientes" (Me Gusta..., [201-]).

Todavia, o dia 8 de março de 2015 foi marcado por constrangimentos para um casal que foi à Me Gusta em São Paulo. Raul Perez e Gabriel Miranda foram à sorveteria, sentaram-se, pediram seus picolés e, após alguns gestos afetivos, comumentemente praticados por casais, como mãos dadas, beijos e conversas, foram interrompidos por um segurança após causarem um suposto "incômodo" a um casal heterossexual. Raul e Gabriel foram convidados a se retirar da loja e o fato gerou indignação ao casal e reverberação nas mídias digitais.

Após o incidente, a imagem da organização foi prejudicada momentaneamente. 0 jornalista Raul Perez publicou na rede social digital Facebook sobre o ocorrido, demonstrando sua indignação e a falta de respeito do funcionário. 0 preconceito tornou a situação, que deveria ser vista como comum, em um cenário de conflitualidade, mas uma oportunidade para 0 diálogo: "Hoje: Nos Jardins, fui expulso de uma palleteria (rs) por beijar meu namorado. 0 segurança disse que aquele era um ambiente familiar. Só mais um domingo nos Brasis" (Perez, 2015).

A mensagem do jornalista alcançou 129 curtidas, 3 compartilhamentos e 50 comentários. Com a replicabilidade do caso, a organização se posicionou rapidamente, recebendo elogios pela postura humano-ética. No dia posterior ao acontecimento, a Me Gusta emitiu uma nota oficial, assumindo o erro. A publicação na página oficial da marca alcançou 25 mil curtidas, 1.800 mil comentários e mais de 4.500 compartilhamentos até o dia 11 de julho de 2017.

Este é um pedido oficial de desculpas. A todos aqueles que acreditam que o amor é que nem sorvete: tem (sic) de todos os tipos, todos os gostos e de todas as cores. Ontem a intolerância falou mais alto na nossa lojinha tão amorosa e querida. Infelizmente. [...] A culpa é da Me Gusta. Trabalhamos com pessoas. Não só com picolés! Devemos saber da conduta das pessoas que empregamos em nosso estabelecimento. Devemos orientar e situar nossos funcionários no século XXI. [...] Devemos focar nossa comunicação na tolerância e falar abertamente de amor ao próximo e humanidade. [...] Nossa política sempre foi em prol da diversidade, da compaixão e do respeito. [...] Por fim, pedimos desculpas a TODOS os clientes da Me Gusta (Bom..., 2015).

Depois da postagem, a empresa interagiu com alguns usuários ${ }^{8}$. As mensagens foram escritas individualmente, tratando cada comentário como único, sendo que o discurso da Me Gusta está investido de sentidos de respeito e cuidado com o Outro. Entre os comentários, um usuário enalteceu a posição da empresa, comentando sua postura em relação aos clientes:

Geeeente, tô passada (sic)!! Passada e emocionada com a resposta dessa empresa. Finalmente uma empresa com uma postura DECENTE, respeitosa e humilde! Que não culpabilizaram (sic) o cliente, não se desfizeram (sic) dele, não negaram (sic) o ocorrido, não os fizeram (sic) de doidos, não responderam (sic) com agressividade! Nem com frieza. Responderam (sic) com amor. (Bom...,2015)

Como resposta ao elogio, a Me Gusta convidou o usuário a conhecer a loja com outras pessoas, dizendo: "essa luta tem que continuar sempre. E com muito amor no coração e respeito a todo mundo!" (Bom..., 2015). Em outro momento, um interagente que não conhecia a marca comentou que a postura da empresa fez que tivesse vontade de ir visitá-la. Como resposta, a Me Gusta the disponibilizou o endereço da loja e fez o convite de "juntos celebrar (sic) o amor e continuar nessa luta!" (Bom..., 2015). 


\section{ALTERIDADE, ÉTICA E INTEGRIDADE EM UM MUNDO DE CONSUMIDORES: O QUE O CASO ME GUSTA NOS ENSINA?}

Ao analisarmos o $\operatorname{caso}^{9}$ Me Gusta, destacamos o posicionamento da marca perante seus stakeholders. A maneira como lidou com os fatos, sua reverberação e as conversações on-line com alguns usuários-mídia, bem como as consequências que foram ocasionadas, aportam-nos elementos cruciais para lançarmos luz sobre a comunicação organizacional, as relações consumeristas e o futuro da humanidade, no âmbito de uma sociedade entremeada por uma cultura de consumo.

$\mathrm{Na}$ atualidade, os consumidores querem ser respeitados por suas identidades e estilos e essa demanda social não é uma opção, senão um princípio basilar para as organizações. Essa questão enaltece a arquitetura dos elementos que compõem esse artigo: sociedade de consumo, ética, integridade e comunicação organizacional. Isso nos coloca perante a urgência de a honestidade entrar na esfera da condição do ser-humano e das práticas empresariais. 0 contexto hodierno nos chama à compreensão das sociedades como fábricas de significações, verdadeiras sementeiras da existência eivadas de sentido e produtoras deles. (Bauman, 2008).

0 caso Me Gusta nos ensina que falta coragem e disposição para estarmos na presença do Outro, porque este pode ser uma promessa, mas também uma ameaça. A humanidade está em crise e "não existe outra saída para ela senão a solidariedade dos seres humanos" (Bauman, 2017, p. 24), ou seja, os obstáculos no caminho são: a recusa ao diálogo, a insensibilidade e 0 desprezo pelo Outro. Na busca pela comunicação bidirecional, temos que, antes de tudo, compreender os motivos que nos levam a nos incomodar com as diferenças, sendo que a alteridade é uma constante nas relações humanas e sociais. Nessa linha, é inegável a influência das marcas na vida dos sujeitos (Semprini, 2006). Paradoxalmente, estão mais expostas aos "ventos" do ecossistema virtual, ficando sujeitas à fragilização, própria da pós-modernidade.

As organizações devem fazer que o consumidor perceba a exclusividade que o tratam, reforçando suas conversações com empatia, respeito e cordialidade: "Ontem a intolerância falou mais alto na nossa lojinha tão amorosa e querida" (Bom..., 2015). 0 relacionamento aberto e próximo ajuda às organizações a desenvolverem a comunicação estratégica, atuando de modo proativo. A gestão das conflitualidades que surgem na ágora virtual faz que as organizações construam identidades mais humanas e coerentes, equilibrando a ética e a estética (Simões, 2001). A árvore da informação e seus frondosos ramos da transmissão escamoteiam a floresta da comunicação e das alteridades. 0 discurso de posicionamento da Me Gusta corrobora esse pensamento: 0 outro não pode ser apenas o outro, senão o Outro igual a nós, digno de respeito e amor, como observamos na nota postada pela marca na rede social Facebook: "Nossa política sempre foi em prol da diversidade, da compaixão e do respeito" (Bom..., 2015).

Nesse mundo frágil, as marcas devem pôr em relevo o fato de que o fácil acesso às várias plataformas de mídia tornou 0 público "mais empoderado para desafiar políticas corporativas" (Jenkins; Ford; Green, 2014, p. 85), mas também de elogiar as marcas: "Finalmente uma empresa com uma postura DECENTE, respeitosa e humilde" (Bom..., 2015). Assim, as diversas formas de participação ativa dos públicos, fiscalizando o comportamento das organizações, como fez o usuário apontado ao comentar e elogiar a iniciativa de resposta da Me Gusta em sua página no Facebook diante do problema de comunicação exposto, são pilares da cultura da propagabilidade erigida com as redes sociais da Internet.

A competição do mercado solapa a solidariedade em um mundo, "incuravelmente fragmentado e atomizado e, portanto, cada vez mais incerto e imprevisível" (Bauman, 2007, p. 20). A ampliação dos contatos entre organizações e públicos estratégicos

90 caso Me Gusta permite ratificar as discussões realizadas anteriormente. Além disso, proporciona-nos ampliar e aplicar os conceitos que mobilizamos para fazermos algumas inferências acerca da ética, alteridade e integridade no contexto de uma sociedade de consumidores. 
incita-nos a valorizar o que Bauman (2011, p. 77) chama de "expressão soberana da vida", a qual se manifesta sob a forma de confiança e compaixão. Apesar da complexidade do cenário atual, a Me Gusta demonstrou, no caso analisado, ter compaixão à situação ofensiva que o casal foi exposto e, a partir disso, conseguiu construir uma relação inicial de confiança em conjunto com os seus stakeholders.

Esse caso transcende a utilização única da comunicação funcional, que se limita a divulgar informações, promovendo a prática da comunicação normativa, haja vista valorizar o respeito, a compreensão e o diálogo (Wolton, 2006). Entretanto, esse posicionamento não é tão recorrente no mundo organizacional. Identificamos um contexto em que a valorização da informação ainda se sobrepõe à comunicação, produzindo incompreensão e mal-estar.

Embora a Me Gusta tenha reconhecido seu erro, poderia ter evitado o ocorrido se tivesse agido estrategicamente, ao sensibilizar seus funcionários sobre a relevância da ética e do respeito em relação às diversas alteridades com as quais se relaciona. $A$ marca parece não se esquivar de suas responsabilidades e erros: "A culpa é da Me Gusta. Trabalhamos com pessoas. Não só com picolés! Devemos saber da conduta das pessoas que empregamos em nosso estabelecimento" (Bom..., 2015).

Na coxia dessas ponderações, cremos que é necessário acompanhar as múltiplas demandas da sociedade e se posicionar em relação a elas. As organizações e os profissionais da comunicação não podem apenas reagir às pressões sociais quando elas interferem em suas atuações e na imagem/reputação organizacional, devem se antecipar a elas por meio de políticas de comunicação ancoradas em valores essenciais à convivência e à coabitação. Desse modo, será possível alcançar certa coerência entre a ética e a estética organizacional/profissional, conforme propõe Simões (2001).

Assim, Lipovetsky (2007) aposta que a sociedade contemporânea não jaz na desesperança, sendo que para ele a utopia de uma democracia pós-consumista pode emergir eivada de fé, tolerância, responsabilidade e respeito. Por sua vez, Bauman (2008) e Morin (2015) afiançam que, sem uma mudança de mentalidade, a restauração da fé nos valores estáveis tem pouca chance de entrar em marcha.

Apesar de esse horizonte recuar sempre que tentamos chegar mais perto, ele representa a possibilidade e a urgência da ética e estética e de uma comunicação organizacional que gere confiança no Outro. É importante frisar que a confiança é, muitas vezes, solapada por um mundo de consumo obcecado pelo poder, corrupção e ausência de integridade (Silva, 2016). A coragem do amor se mede pela virtude do reconhecimento daquilo que no Outro "nos é apresentado sob a forma da diferença - e mesmo assim ser capaz de acolher essa alteridade", como pontuam Bauman e Dessal (2017, p. 9). As alteridades habitam um mundo complexo, plural, caleidoscópico, mas que carece eliminar a dificuldade de assumir erros: "não culpabilizaram (sic) o cliente, não se desfizeram (sic) dele, não negaram (sic) o ocorrido [...] Responderam (sic) com amor" (Bom..., 2015).

Nessa esteira, melhorar as condições de vida depende da nossa capacidade subdesenvolvida de compreender o Outro e de amar. Morin (2011, p. 105) assevera que a ética exige abertura ao Outro, pois salvaguarda o sentimento de identidade comum, consolida e tonifica a compreensão, levando em conta que "cortesia e civilidade não podem ser consideradas como disposições anódinas, pois são signos de reconhecimento do outro como pessoa".

Ao optarmos pelo caso da sorveteria Me Gusta, buscamos fugir à perspectiva do niilismo pessimista, apostando na vida, no respeito e em "todas as formas que a dignidade humana pode adotar" (Bauman; Dessal, 2017, p. 24). Isso também porque as investigações em comunicação organizacional focam, amiúde, na crítica voraz às práticas corporativas, deixando de lado algumas experiências que colaboram com a transformação do mundo, geram esperança e alumiam as possibilidades de sobrevivência ética de nossa espécie - ainda que em um microuniverso e pontualmente. 
A ação corrosiva do discurso neoliberal encontra cada vez menos óbices para transformar cada sujeito em mercadoria, ampliando os mapas da coisificação. Conforme os laços sociais se esgarçam, as chances de povoarmos o mundo com sujeitos, comunidades, organizações e Estados capazes de gerar a convivência nas/das diversidades, torna-se improvável. Todavia, 0 discurso e posicionamento da marca Me Gusta no caso que analisamos, torna-se, assim, uma esperança que pavimenta as estradas que podem nos levar a esse mundo.

\section{REFERÊNCIAS}

ALMEIDA, Filipe J. R. Ética e desempenho social das organizações: um modelo teórico de análise dos fatores culturais e contextuais. Revista de Administração Contemporânea, Curitiba, v. 11, n. 3, p. 105-125, jul./set. 2007.

BAUMAN, Zygmunt. Modernidade e ambivalência. Trad. de Marcus Penchel. Rio de Janeiro: Zahar, 1999.

Ética pós-moderna. Trad. de João Rezende Costa. 2. ed. São Paulo: Paulus, 2003.

Tempos líquidos. Trad. de Carlos Alberto Medeiros. Rio de Janeiro: Zahar, 2007.

Vida para consumo: a transformação das pessoas em mercadoria. Trad. de Carlos Alberto Medeiros. Rio de Janeiro: Zahar, 2008.

. A ética é possível num mundo de consumidores?Trad. de Alexandre Vieira Werneck. Rio de Janeiro: Zahar, 2011.

. Estranhos à nossa porta. Trad. de Carlos Alberto Medeiros. Rio de Janeiro: Zahar, 2017.

BAUMAN, Zygmunt; DESSAL, Gustavo. O retorno do pêndulo: sobre a psicanálise e o futuro do mundo líquido. Trad. de Joana Angélica d'Avila Melo. Zahar: Rio de Janeiro, 2017.

BOM DIA, PESSOAL! Este é um pedido oficial de desculpas... Me Gusta Picolés Artesanais, [São Paulo], 2015. Disponível em: <https://goo.gl/3KfXp6>. Acesso em: 11 jul. 2017.

BUENO, Wilson C. Comunicação empresarial: alinhando teoria e prática. São Paulo: Manole, 2014.

CANCLINI, Néstor G. Consumidores e cidadãos. Trad. de Maurício Santana Dias. 9. ed. Rio de Janeiro: Editora UFRJ, 2010.

CORRÊA, Elisabeth S. A comunicação na sociedade digitalizada: desafios para as organizações contemporâneas. In: KUNSCH, Margarida M. K. (Org.) Comunicação Organizacional Estratégica: aportes conceituais e aplicados. São Paulo: Summus, 2016. p. 59-76.

DREYER, Bianca M. Relações públicas na contemporaneidade: contexto, modelos e estratégias. São Paulo: Summus, 2017.

KUNSCH, Margarida M. K. A comunicação nas organizações: dos fluxos lineares às dimensões humana e estratégica. In: . (Org.) Comunicação Organizacional Estratégica: aportes conceituais e aplicados. São Paulo: Summus, 2016. p. 37-58.

JENKINS, Henry; FORD, Sam. GREEN, Joshua. Cultura da conexão: criando valor e significado por meio da mídia propagável. Trad. de Patricia Arnaud. São Paulo: Aleph, 2014. 
LIPOVETSKY, Gilles. A era do vazio: ensaios sobre o individualismo contemporâneo. Trad. de Therezinha Monteiro Deutsch. Barueri: Manole, 2005.

. A sociedade da decepção. Trad. de Armando Braio Ara. Barueri: Manole, 2007.

LIPOVETSKY, Gilles; SERROY, Jean. A cultura-mundo: resposta a uma sociedade desorientada. Trad. de Maria Lúcia Machado. São Paulo: Companhia das Letras, 2011.

ME GUSTA PICOLÉS ARTESANAIS. Nosso jeito. [São Paulo], [201-]. Disponível em: <https://goo.gl/iUFGYZ>. Acesso em: 11 jul. 2017.

MORIN, Edgar. O método 6: ética. Trad. de Juremir Machado da Silva. Porto Alegre: Sulina, 2011.

. A Via para o futuro da humanidade. Trad. de Edgard de Assis Carvalho e Mariza Perassi Bosco. 2. ed. Rio de Janeiro: Bertrand Brasil, 2015.

PEREZ, Raul. Hoje: No Grajaú... Facebook, São Paulo, 2015. Disponível em: <https://goo.gl/8SYstc>. Acesso em: 11 jul. 2017.

SEMPRINI, Andrea. A marca pós-moderna: poder e fragilidade da marca na sociedade contemporânea. Trad. de Elisabeth Leone. São Paulo: Estação das Letras, 2006.

SILVA, Marcelo. A comunicação corporativa e o discurso do consumidor contemporâneo nos sites sociais de reclamação: decepção e coabitação na rede - desafios e oportunidades. 2016. 291 f. Tese (Doutorado em Comunicação Social) - Escola de Comunicação, Educação e Humanidades, Universidade Metodista de São Paulo, São Bernardo do Campo, 2016.

SIMÕES, Roberto P. Relações públicas e micropolítica. São Paulo: Summus, 2001.

SROUR, Robert H. Poder, cultura e ética nas organizações. 3. ed. rev. Rio de Janeiro: Elsevier, 2012.

WOLTON, Dominique. É preciso salvar a comunicação. Trad. de Vanise Pereira Dresch. São Paulo: Paulus, 2006.

Texto recebido em 27.07.2017 e aprovado em 06.11.2017. 